\title{
Lead (II) Adsorption on Chemically Modified Activated Carbon in Aqueous Solution
}

\author{
Fumihiko Ogata, Yuka Iwata, and Naohito Kawasaki* \\ Faculty of Pharmacy, Kinki University, 3-4-1 Kowakae, Higashi-Osaka, Osaka 577-8502, Japan
}

(Received 24 July 2013; Accepted 21 August 2013; Published 31 August 2013)

\begin{abstract}
In the present study, we developed modified activated carbon (KL) for the adsorption of $\mathrm{Pb}$ (II). Chemically modified activated carbons (KL-A and KL-B) were prepared by nitric acid and ethylenediamine treatments, respectively. The properties (specific surface area, pore volume, mean pore diameter, acidic or basic functional groups, and $\mathrm{pH}$ ) of $\mathrm{KL}, \mathrm{KL}-\mathrm{A}$, and KL-B were investigated by various methods. Contact time, adsorption isotherms, and recovery of $\mathrm{Pb}(\mathrm{II})$ were evaluated. Equilibrium adsorption on KL and KL-B or KL-A was reached in about $12 \mathrm{~h}$ and $5 \mathrm{~h}$, respectively. The experimental data was fitted to pseudo-second order model and compared with the pseudo-first order model. The optimal $\mathrm{pH}$ conditions for the adsorption of $\mathrm{Pb}$ (II) was $\mathrm{pH}=5.1-5.5$. These data were fitted to Freundlich and Langmuir models. Moreover, the adsorption mechanism of Pb (II) on KL-A was related to the ion exchange with acidic functional groups. It would be possible to recover $\mathrm{Pb}$ (II) by using nitric acid. The results suggest that KL-A would be useful in the adsorption of Pb (II). [DOI: 10.1380/ejssnt.2013.93]
\end{abstract}

Keywords: Lead; Adsorption; Activated carbon; Chemical modification

\section{INTRODUCTION}

Heavy metals are discharged from various industries, such as electroplating, metal finishing, textile, storage batteries, mining, ceramic, and glass industries [1]. Lead poisoning or exposure can cause hypertension, nephritis, abdominal pain, constipation, cramps, nausea, vomiting, behavioral changes, learning disabilities, reading problems, development defects, and language difficulties [2, 3]. The maximum permissible limit assigned by World Health Organization (WHO) for $\mathrm{Pb}$ (II) in drinking water is $0.05 \mathrm{mg} / \mathrm{L}[4]$. A number of techniques have been developed for removing lead pollutants from aqueous effluents to minimize their impact. Although traditional treatment methods, such as precipitation, oxidation, reduction, electrochemical treatment, reverse osmosis, solvent extraction, adsorption, ion exchange, and evaporation, can be used for metal-containing effluents, most of these methods are expensive and difficult to apply $[5,6]$. Among these methods, adsorption is an attractive process, in view of its efficiency and ease of use [7].

Activated carbons are the major adsorbents used in water treatment plants because the large specific surface area of activated carbon provides adsorption sites for contaminating organic compounds, especially for aromatics, such as phenol and nitrobenzene [8-11]. In contrast, heavy metal adsorption on activated carbon has been considered to take place mainly at acidic functional groups, such as carboxylic and lactonic groups $[12,13]$. It is well known that the surface properties and physical and chemical properties of activated carbons have significant effect on the adsorption performance. Zhenhua et al. reported the metal ion adsorption capacity of activated carbon modified with ethylenediamine [14]; however, the properties of the modified activated carbon were not investigated in detail. Moreover, the concentration of metal ions in the adsorption experiments was very low, and the relationship between the adsorbed amount and the properties of activated carbon was not discussed. The object of this study is therefore to reveal the properties of activated carbon

*Corresponding author: kawasaki@phar.kindai.ac.jp

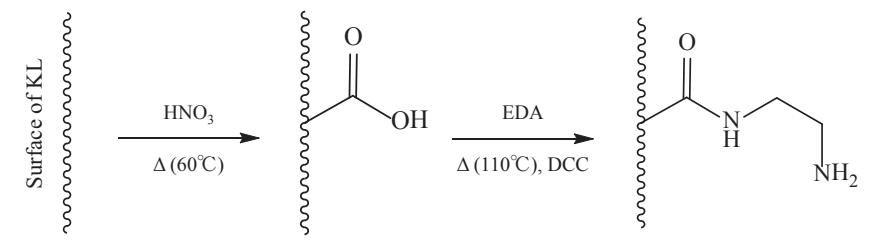

FIG. 1: Schematic illustration of activated carbon functionalization.

treated with nitric acid or ethylenediamine, and then elucidate the adsorption mechanism of $\mathrm{Pb}$ (II) on chemically modified activated carbon.

\section{EXPERIMENTAL METHODS}

\section{A. Materials}

Activated carbon (KL, Shirasagi series) was purchased from Japan EnviroChemicals, Ltd. KL was washed with distilled water, and subsequently filtered using a $0.45-\mu \mathrm{m}$ membrane filter. Filtered KL was used for the experiments. A standard solution of $\mathrm{Pb}$ (II) and all other reagents were purchased from Wako Pure Chemical Industries, Ltd. KL was first purified by treating with $10 \%$ $(\mathrm{v} / \mathrm{v})$ hydrochloric acid solution for $24 \mathrm{~h}$ to remove metal ions and other impurities. Then, $10 \mathrm{~g}$ of KL was suspended in $300 \mathrm{~mL}$ of $32.5 \%(\mathrm{v} / \mathrm{v})$ nitric acid solution under stirring and heated for $5 \mathrm{~h}$ at $60^{\circ} \mathrm{C}$. The mixture was filtered, and the residue was washed with deionized water until the washings were neutral, and dried at $70^{\circ} \mathrm{C}$ for $24 \mathrm{~h}$. The product was a carboxylic acid derivative of activated carbon (KL-A).

For the synthesis of ethylenediamine-modified activated carbon (KL-B), $10 \mathrm{~g}$ of KL-A was suspended in $150 \mathrm{~mL}$ of ethylenediamine. Then, $10 \mathrm{~g}$ of $N, N^{\prime}$ dicyclohexylcarbodiimide (DCC) was added into the sus-

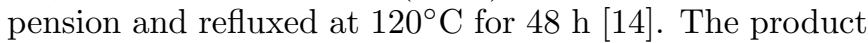
(KL-B) was filtered off, washed with ethanol, and dried at $70^{\circ} \mathrm{C}$ for $24 \mathrm{~h}$. The synthetic routes for KL-A and KL-B 

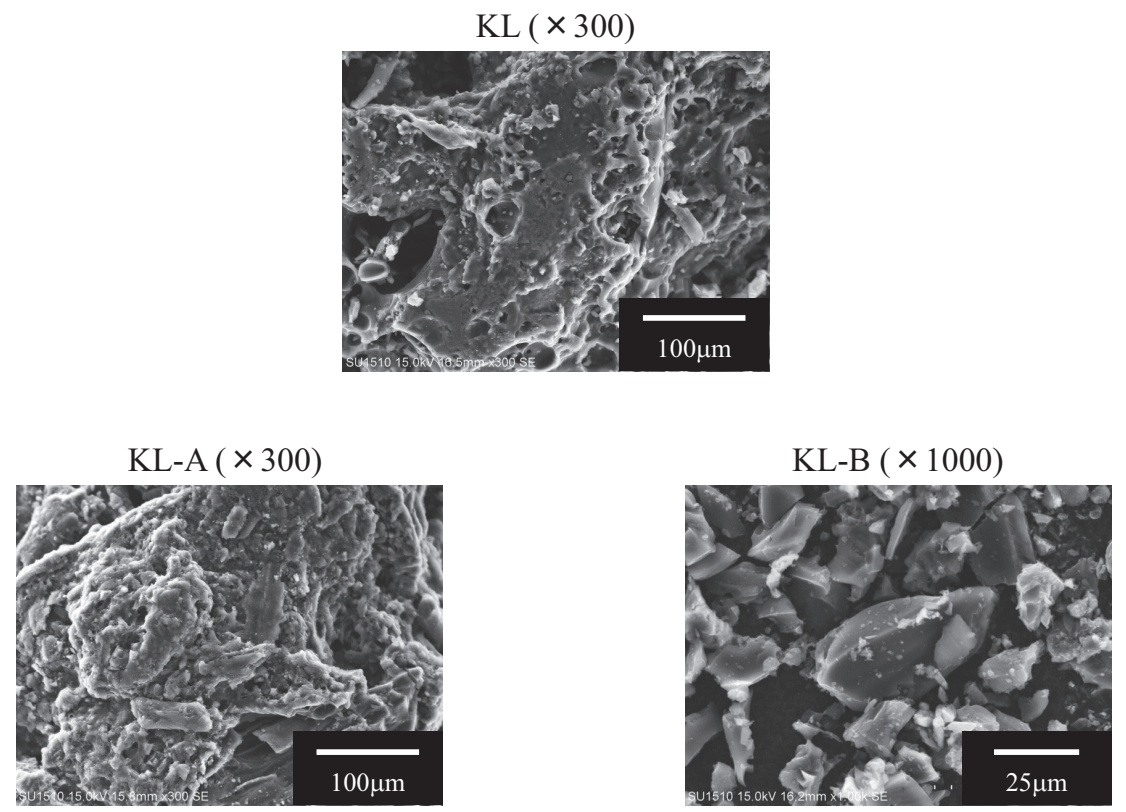

FIG. 2: SEM images of KL, KL-A, and KL-B.

are illustrated in Fig. 1.

\section{B. Methods}

Scanning electron microscopy (SEM) was carried out using a JSM-5500LV system (JEOL, Japan). The specific surface area, mean pore diameter, and pore volume of KLs were measured using a NOVA4200e surface area analyzer (Yuasa Ionic, Japan). The number of surface functional groups was measured by a titration method [15]. The $\mathrm{pH}$ of the solution after the addition of KLs was measured by an activated carbon test method (JIS K1474).

\section{Effect of contact time on the adsorption of $\mathrm{Pb}$} (II)

Adsorbent $(0.015 \mathrm{~g})$ was added to $50 \mathrm{~mL}$ of $10 \mathrm{mg} / \mathrm{L}$ $\mathrm{Pb}$ (II) solution. The suspensions were shaken at $25^{\circ} \mathrm{C}$ for $0.05-18 \mathrm{~h}$ at $100 \mathrm{rpm}$, and then filtered using a 0.45 $\mu \mathrm{m}$ membrane filter. The concentration of the solution was measured by inductively coupled plasma-atomic emission spectroscopy (ICP-AES, Shimadzu). The adsorbed amount was calculated from the concentrations before and after the adsorption using Eq. (1):

$$
q=\left(C_{0}-C_{e}\right) V / W,
$$

where $q(\mathrm{mg} / \mathrm{g})$ is the adsorbed amount, $C_{0}(\mathrm{mg} / \mathrm{L})$ is the initial concentration, $C_{e}(\mathrm{mg} / \mathrm{L})$ is the equilibrium concentration, $V(\mathrm{~L})$ is the solvent volume, and $W(\mathrm{~g})$ is the weight of the adsorbent.

\section{Adsorption isotherms of $\mathrm{Pb}$ (II) on KLs}

Adsorbent $(0.015 \mathrm{~g})$ was added to $50 \mathrm{~mL}$ of $\mathrm{Pb}$ (II) solution at different concentrations ( $\mathrm{pH}$ ranges 3.0-3.8,
3.9-4.8, and 5.1-5.5), and the suspensions were shaken at $100 \mathrm{rpm}$ for $24 \mathrm{~h}$ at $25^{\circ} \mathrm{C}$. The solution was then filtered using a $0.45-\mu \mathrm{m}$ membrane filter, and the concentration of $\mathrm{Pb}$ (II) was determined by ICP-AES. The amount of the adsorbed $\mathrm{Pb}$ (II) was calculated using Eq. (1).

\section{E. Recovery of $\mathrm{Pb}$ (II) using nitric acid solution}

Adsorbent $(0.1 \mathrm{~g})$ was added to $50 \mathrm{~mL}$ of $20 \mathrm{mg} / \mathrm{L} \mathrm{Pb}$ (II) solution, and the suspensions were shaken at $100 \mathrm{rpm}$ for $24 \mathrm{~h}$ at $25^{\circ} \mathrm{C}$. The solution was then filtered using a $0.45-\mu \mathrm{m}$ membrane filter, and the concentration of $\mathrm{Pb}$ (II) was determined by ICP-AES. The amount of adsorbed $\mathrm{Pb}$ (II) was calculated using Eq. (1). The filtered adsorbent was dried at room temperature, and added to $50 \mathrm{~mL}$ of 10 or $100 \mathrm{mmol} / \mathrm{L}$ nitric acid solution. The suspensions were shaken at $100 \mathrm{rpm}$ for $24 \mathrm{~h}$ at $25^{\circ} \mathrm{C}$. The solution was then filtered using a $0.45-\mu \mathrm{m}$ membrane filter, and the concentration of $\mathrm{Pb}$ (II) was determined by ICP-AES. The amount of desorbed $\mathrm{Pb}$ (II) was calculated using Eq. (2).

$$
d=C_{e} V / W,
$$

where $d(\mathrm{mg} / \mathrm{g})$ is the desorbed amount, $C_{e}(\mathrm{mg} / \mathrm{L})$ is the equilibrium concentration, $V(\mathrm{~L})$ is the solvent volume, and $W(\mathrm{~g})$ is the weight of the adsorbent.

\section{RESULTS AND DISCUSSION}

\section{A. Properties of KLs}

SEM images of KL, KL-A, and KL-B are shown in Fig. 2. The particle diameters decreased in the order: KL-B $<$ KL-A $<$ KL. The surface of KL and KL-A was observed to be uneven, whereas the surface of KL-B was observed to be smooth. The physical and chemical properties of the activated carbons are listed in Tables I and 
TABLE I: Physical properties of ACs.

\begin{tabular}{|c|c|c|c|c|c|}
\hline \multirow[t]{2}{*}{$\mathrm{ACs}$} & \multirow{2}{*}{$\begin{array}{c}\text { Specific surface } \\
\text { area }\left(\mathrm{m}^{2} / \mathrm{g}\right)\end{array}$} & \multicolumn{3}{|c|}{ Pore volume $(\mathrm{mL} / \mathrm{g})$} & \multirow{2}{*}{$\begin{array}{c}\text { Mean pore } \\
\text { diameter }(\AA)\end{array}$} \\
\hline & & $r \leq 10 \AA$ & $10<r \leq 250 \AA$ & Total & \\
\hline $\mathrm{KL}$ & 1542 & 0.05 & 0.86 & 0.91 & 23.6 \\
\hline KL-A & 1267 & 0.06 & 0.54 & 0.60 & 18.9 \\
\hline KL-B & 771 & 0.04 & 0.66 & 0.70 & 21.1 \\
\hline
\end{tabular}

TABLE II: Chemical properties of ACs.

\begin{tabular}{|c|c|c|c|c|c|c|}
\hline \multirow[t]{2}{*}{$\mathrm{ACs}$} & \multicolumn{4}{|c|}{ Acidic functional groups (mmol/g) } & \multirow{2}{*}{$\begin{array}{l}\text { Basic functional } \\
\text { groups (mmol/g) }\end{array}$} & \multirow[t]{2}{*}{$\mathrm{pH}$} \\
\hline & Total & Phenolic & Lactonic & Carboxyl & & \\
\hline $\mathrm{KL}$ & 1.04 & 0.43 & 0.00 & 0.61 & 0.00 & 4.86 \\
\hline KL-A & 2.39 & 0.99 & 0.07 & 1.33 & 0.01 & 2.95 \\
\hline KL-B & 0.94 & 0.43 & 0.21 & 0.30 & 1.21 & 7.86 \\
\hline
\end{tabular}

II. The specific surface areas decreased in the order: KLB $\left(771 \mathrm{~m}^{2} / \mathrm{g}\right)<\mathrm{KL}-\mathrm{A}\left(1267 \mathrm{~m}^{2} / \mathrm{g}\right)<\mathrm{KL}\left(1542 \mathrm{~m}^{2} / \mathrm{g}\right)$. In contrast, the mean pore diameters followed the order KL-A $(18.9 \AA)<\operatorname{KL-B}(21.1 \AA)<\mathrm{KL}(23.6 \AA)$. The pore volumes showed a trend similar to that observed for mean pore diameters. These results indicate that specific surface area of activated carbon decreased with chemical modification.

The number of phenolic functional groups (0.99 mmol/g) and carboxyl functional groups $(1.33 \mathrm{mmol} / \mathrm{g})$ on KL-A were higher after the nitric acid treatment of KL. The number of basic functional groups $(1.21 \mathrm{mmol} / \mathrm{g})$ on KL-B increased following the DCC treatment. These results suggest that carboxyl and basic functional groups were generated on the surface by the treatments above (see Section II.A). The $\mathrm{pH}$ of the solution for KL, KL-A, and KL-B were 4.86, 2.95, and 7.86 , respectively.

\section{B. Effect of contact time on $\mathrm{Pb}$ (II) adsorption on} KL, KL-A, and KL-B

Effect of contact time on the $\mathrm{Pb}$ (II) adsorption on KL, KL-A, and KL-B is shown in Fig. 3. The amounts of adsorbed $\mathrm{Pb}(\mathrm{II})$ followed the order: $\mathrm{KL} \cong \mathrm{KL}-\mathrm{B}<\mathrm{KL}-$ A. Equilibrium adsorption times for KL and KL-B or KLA were about $12 \mathrm{~h}$ and $5 \mathrm{~h}$, respectively. Hence, the adsorption rate of $\mathrm{Pb}$ (II) was higher on KL-A than on KL.

Lagergren pseudo-first order rate equation is widely used for describing the adsorption in liquid/solid system based on solid capacity [16]. The pseudo-first order rate equation is given by:

$$
\ln \left(q_{e}-q_{t}\right)=\ln q_{e}-k_{1} t
$$

where $k_{1}$ is the Lagergren rate constant of adsorption $(1 / \mathrm{h}), q_{e}$ is the amount of solute adsorbed at equilibrium $(\mathrm{mg} / \mathrm{g})$, and $q_{t}$ is the amount of solute adsorbed on the surface of the adsorbent at time $t(\mathrm{mg} / \mathrm{g})$.

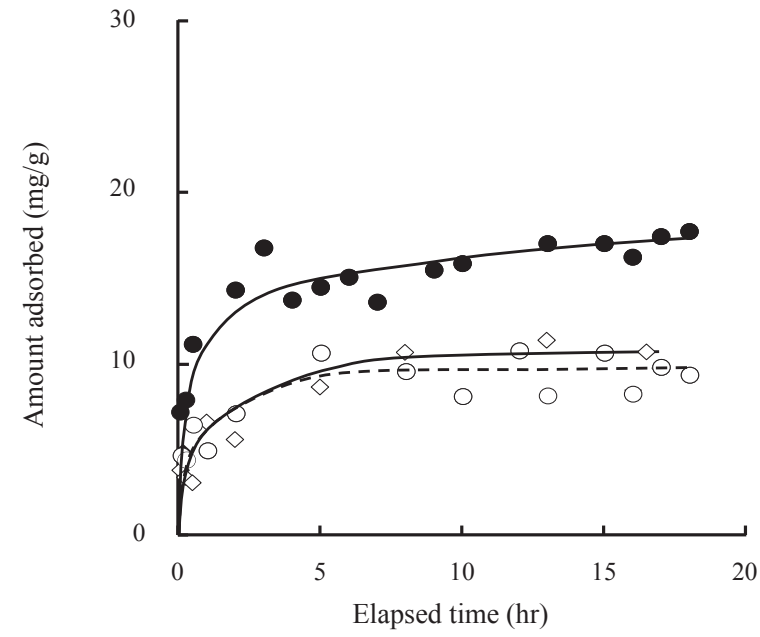

FIG. 3: Effect of contact time for adsorption of $\mathrm{Pb}$ (II) onto KL, KL-A, and KL-B. $\diamond:$ KL, •: KL-A, ०: KL-B.

Pseudo-second order rate equation, derived by Ho and Mckay, is one of the most widely used kinetic expressions [17]. In this equation, adsorption capacity is assumed to be directly proportional to the number of occupied active sites on the adsorbent [16]. The pseudo-second order rate equation could be expressed as:

$$
t / q_{t}=1 /\left\{k_{2} q_{e}^{2}\right\}+t / q_{e},
$$

where $k_{2}$ is the pseudo-second order rate constant of adsorption $(\mathrm{g} / \mathrm{mg} \mathrm{h}), q_{e}$ is the amount of solute adsorbed at equilibrium $(\mathrm{mg} / \mathrm{g})$, and $q_{t}$ is the amount of solute adsorbed on the surface of the adsorbent at time $t(\mathrm{mg} / \mathrm{g})$.

The correlation coefficient $(r)$ and pseudo-first or pseudo-second order constant $\left(k_{1}\right.$ or $\left.k_{2}\right)$ for these models are summarized in Table III. The correlation coefficient $r$ for pseudo-second order kinetic model is much higher than that for the pseudo-first order model, and the adsorption capacities calculated by the former model are close to the experimental results. Therefore, it can be concluded that the pseudo-second order adsorption model is more suitable for describing the adsorption kinetics of $\mathrm{Pb}$ (II) on 
TABLE III: Constants of kinetics model for adsorption of $\mathrm{Pb}(\mathrm{II})$ onto ACs.

\begin{tabular}{|c|c|c|c|c|c|c|c|}
\hline \multirow[t]{2}{*}{$\mathrm{ACs}$} & \multirow{2}{*}{$\begin{array}{c}q_{e, e x p} \\
(\mathrm{mg} / \mathrm{g})\end{array}$} & \multicolumn{3}{|c|}{ PFOM } & \multicolumn{3}{|c|}{ PSOM } \\
\hline & & $k_{1}(1 / \mathrm{hr})$ & $q_{e, c a l}(\mathrm{mg} / \mathrm{g})$ & $r$ & $k_{2} \times 10^{-2}(\mathrm{~g} / \mathrm{mg} / \mathrm{hr})$ & $q_{e, c a l}(\mathrm{mg} / \mathrm{g})$ & $r$ \\
\hline $\mathrm{KL}$ & 9.50 & 0.38 & 4.41 & 0.261 & 2.49 & 10.45 & 0.990 \\
\hline KL-A & 17.77 & 1.51 & 6.11 & 0.532 & 1.77 & 17.10 & 0.989 \\
\hline KL-B & 9.89 & 3.00 & 4.38 & 0.478 & 4.82 & 8.94 & 0.930 \\
\hline
\end{tabular}

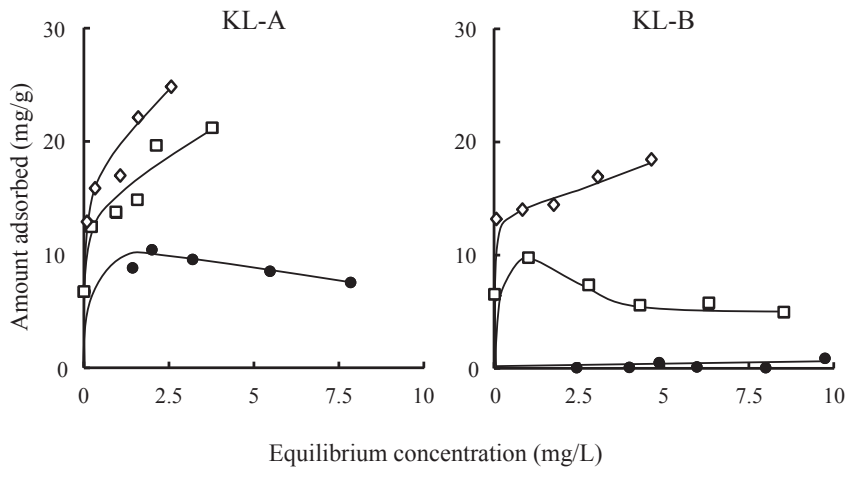

FIG. 4: Adsorption isotherms of $\mathrm{Pb}(\mathrm{II})$ adsorbed by KL-A and KL-B. •: pH 3.0-3.8, $\square: \mathrm{pH} 3.9-4.8, \diamond: \mathrm{pH}$ 5.1-5.5.

KLs.

\section{Adsorption isotherms of $\mathrm{Pb}$ (II) on $\mathrm{KL}-\mathrm{A}$ and KL-B}

Adsorption isotherms of $\mathrm{Pb}$ (II) on KL-A and KL-B are shown in Fig. 4. The values of maximum adsorption of $\mathrm{Pb}$ (II) on KL-A and KL-B in the $\mathrm{pH}$ range 5.1-5.5 were $24.7 \mathrm{mg} / \mathrm{g}$ and $18.4 \mathrm{mg} / \mathrm{g}$, respectively. The amount adsorbed on KL-A and KL-B increased with $\mathrm{pH}$. The Langmuir and Freundlich isotherm models are generally used to simulate the adsorption isotherms. The Langmuir model assumes that adsorption occurs on a monolayer where all adsorption sites are identical and energetically equivalent [18]. The model can be described by the following equation:

$$
q_{e}=a W_{s} C_{e} /\left(1+a C_{e}\right),
$$

where $C_{e}$ is the equilibrium concentration of $\mathrm{Pb}$ (II) remaining in the solution $(\mathrm{mg} / \mathrm{L}), q_{e}$ is the amount of $\mathrm{Pb}$ (II) adsorbed after equilibrium, $W_{s}$, the maximum adsorption capacity, is the amount of adsorbate at complete monolayer coverage $(\mathrm{mg} / \mathrm{g})$, and $a(\mathrm{~L} / \mathrm{mg})$ is a constant that is related to the heat of adsorption.

The Freundlich isotherm model applies to several kinds of adsorption sites on the solid surface, and represents the adsorption at low and intermediate concentrations on heterogeneous surfaces [19]. The model is represented by the following equation:

$$
\log q_{e}=\log K+\{1 / n\} \log C_{e},
$$

where $K$ is the adsorption capacity when $\mathrm{Pb}$ (II) equilibrium concentration is equal to 1 , and $n$ is the degree of the dependence of adsorption on equilibrium concentration.

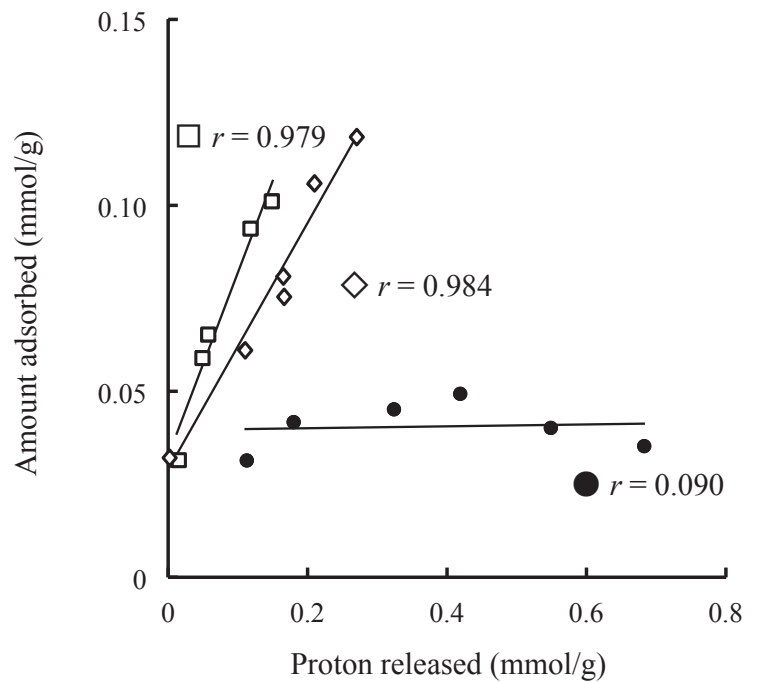

FIG. 5: Relationship between amount of $\mathrm{Pb}(\mathrm{II})$ adsorbed by KL-A and amount of proton released from KL-A. •: pH 3.03.8, $\square: \mathrm{pH} 3.9-4.8, \diamond: \mathrm{pH} 5.1-5.5$.

The values calculated from the two models are listed in Table IV. The correlation coefficients $(r)$ of Freundlich and Langmuir equations using KL-A $(\mathrm{pH}=5.1-5.5)$ are 0.952 and 0.914 , respectively, which indicates that the experimental data of adsorption isotherms fitted well to both Freundlich and Langmuir equations. The optimal $\mathrm{pH}$ conditions for the maximum adsorption $\left(W_{s}\right)$ of $\mathrm{Pb}$ (II) was $\mathrm{pH}=5.1-5.5$. These results show a trend similar to the amount of adsorbed $\mathrm{Pb}$ (II). Moreover, when the Freundlich constant, $1 / n$, is in the range $0.1-0.5$, the adsorption occurs easily. On the other hand, if $1 / n>2$, the adsorption is considered to be difficult [20]. The Freundlich constant $1 / n$ for $\mathrm{Pb}$ (II) is in the range of $0.05-0.53$ (except for $\mathrm{KL}$ and KL-B at $\mathrm{pH}=3.0-3.8$ ). These results show that $\mathrm{Pb}$ (II) was easily adsorbed on KL-A.

\section{Adsorption mechanism of $\mathrm{Pb}$ (II) on KL-A}

Previous reports have shown that the adsorption mechanism of $\mathrm{Pb}$ (II) on different acidic functional groups (carboxyl and lactonic groups) on activated carbon is ion exchange [21]. In this study, we investigated the adsorption mechanism of $\mathrm{Pb}$ (II) on KL-A. The relationship between the amount of $\mathrm{Pb}$ (II) adsorbed by KL-A and the amount of protons released from KL-A is shown in Fig. 5. The amount of protons released was calculated from the proton concentration before and after the adsorption of $\mathrm{Pb}$ (II). The amount of $\mathrm{Pb}$ (II) adsorbed on KL-A was 
TABLE IV: Freundlich and Langmuir constants for adsorption of $\mathrm{Pb}(\mathrm{II})$ onto ACs.

\begin{tabular}{|c|c|c|c|c|c|c|c|}
\hline \multirow[t]{2}{*}{$\mathrm{ACs}$} & \multirow[t]{2}{*}{$\mathrm{pH}$} & \multicolumn{3}{|c|}{ Freundlich model } & \multicolumn{3}{|c|}{ Langmuir model } \\
\hline & & $\log K$ & $1 / n$ & $r$ & $W_{s}(\mathrm{mg} / \mathrm{g})$ & $a(\mathrm{~L} / \mathrm{mg})$ & $r$ \\
\hline \multirow[t]{3}{*}{$\mathrm{KL}$} & $3.0-3.8$ & 1.15 & -1.21 & 0.978 & 0.7 & -0.4 & 0.860 \\
\hline & $3.9-4.8$ & 0.97 & 0.53 & 0.961 & 3.0 & -1.1 & 0.990 \\
\hline & $5.1-5.5$ & 1.01 & 0.11 & 0.944 & 8.6 & -35.3 & 0.854 \\
\hline \multirow[t]{3}{*}{ KL-A } & $3.0-3.8$ & 0.91 & 0.05 & 0.524 & 8.8 & 71.9 & 0.756 \\
\hline & $3.9-4.8$ & 1.18 & 0.20 & 0.894 & 18.2 & 7.3 & 0.771 \\
\hline & $5.1-5.5$ & 1.28 & 0.21 & 0.952 & 22.0 & 9.0 & 0.914 \\
\hline \multirow[t]{3}{*}{ KL-B } & $3.0-3.8$ & -2.89 & 2.82 & 0.724 & -0.1 & -0.1 & 0.742 \\
\hline & $3.9-4.8$ & 0.99 & 0.07 & 0.320 & 11.7 & 7.1 & 0.607 \\
\hline & $5.1-5.5$ & 1.27 & 0.05 & 0.832 & 19.4 & 109.2 & 0.738 \\
\hline
\end{tabular}

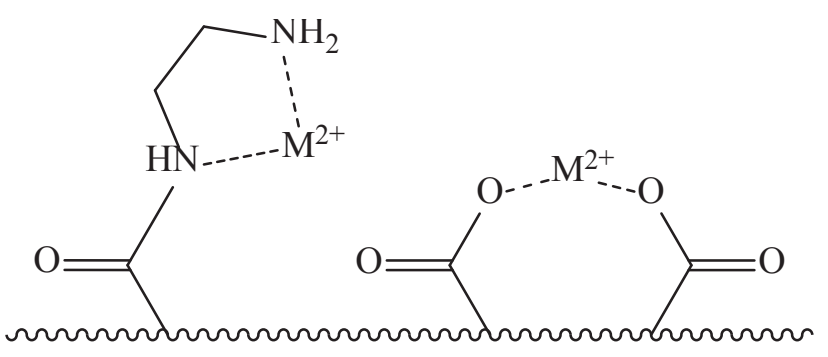

Surface of KL-A and KL-B

FIG. 6: Adsorption mechanism of $\mathrm{Pb}(\mathrm{II})$ by KL-A and KL-B.

TABLE V: Recovery percentage of $\mathrm{Pb}(\mathrm{II})$ using nitric acid.

\begin{tabular}{lcccc}
\hline \hline ACs & $\begin{array}{c}\text { Concentration } \\
\text { of } \mathrm{HNO}_{3} \\
(\mathrm{mmol} / \mathrm{L})\end{array}$ & $\begin{array}{c}\text { Amount } \\
\text { adsorbed } \\
(\mathrm{mg} / \mathrm{g})\end{array}$ & $\begin{array}{c}\text { Amount } \\
\text { desorbed } \\
(\mathrm{mg} / \mathrm{g})\end{array}$ & $\begin{array}{c}\text { Recovery } \\
\text { percentage } \\
(\%)\end{array}$ \\
\hline KL-A & 10 & 9.28 & 3.93 & 42.3 \\
\hline KL-B & 100 & 8.94 & 4.72 & 52.8 \\
& 10 & 9.96 & 3.73 & 37.4 \\
& 100 & 9.96 & 3.97 & 39.8 \\
\hline \hline
\end{tabular}

strongly correlated to the amount of protons released from KL-A (except for $\mathrm{pH}=3.0-3.8$ ). At $\mathrm{pH}$ values 5.1-5.5 and $3.9-4.8$, the ratio of the amounts of adsorbed $\mathrm{Pb}$ (II) and protons released from KL-A was about 1:2 (correlation coefficients: $0.979(\mathrm{pH}=3.9-4.8)$ and $0.984(\mathrm{pH}=5.1-5.5))$. These results indicate that ion exchange occurred in this study. (The adsorption mechanism of $\mathrm{Pb}$ (II) by KL-A and KL-B is shown in Fig. 6 [14].) In acidic solution at $\mathrm{pH}=3.0-3.8$, the protons were not easily released from KL-A and thus, the adsorbed amount was lower than at higher $\mathrm{pH}$ values.

\section{E. Recovery of $\mathrm{Pb}$ (II) using nitric acid solution}

The percent recovery of $\mathrm{Pb}$ (II) from KL-A and KL-B is shown in Table $\mathrm{V}$. The percent recoveries of $\mathrm{Pb}$ (II) from KL-A and KL-B were 42.3-52.8\% and 37.4-39.8\%, respectively. The percent recovery of $\mathrm{Pb}$ (II) increased with the concentration of nitric acid, which suggests that using nitric acid would be useful in the recovery of $\mathrm{Pb}$ (II).

\section{CONCLUSIONS}

KL-A and KL-B were prepared by nitric acid and DDC treatments, respectively. Specific surface areas followed the order: KL-B $\left(771 \mathrm{~m}^{2} / \mathrm{g}\right)<\mathrm{KL}-\mathrm{A}\left(1267 \mathrm{~m}^{2} / \mathrm{g}\right)<\mathrm{KL}$ $\left(1542 \mathrm{~m}^{2} / \mathrm{g}\right)$. The numbers of acidic functional groups of KL-A or basic functional groups of KL-B were higher than for KL. The experimental data for the contact time required for the adsorption of $\mathrm{Pb}$ (II) were fitted to the pseudo-second order model. Moreover, the adsorption isotherms of $\mathrm{Pb}$ (II) were fitted to both Freundlich and Langmuir models. $\mathrm{Pb}$ (II) was adsorbed onto KL-A by ion exchange with the protons of the surface functional groups on KL-A. It would be possible to recover $\mathrm{Pb}$ (II) from KL-A using nitric acid solution. These results suggest that KL-A would be useful for the adsorption of $\mathrm{Pb}$ (II).

\section{Acknowledgments}

This work was financially supported by "Antiaging Center Project" for Private Universities from Ministry of Education, Culture, Sports, Science and Technology, 2008-2012.
[1] K. Jiang, T.-H. Sun, L.-N. Sun, and H.-B. Li, J. Environ. Sci. 18, 1221 (2006).

[2] X. L. Song, H. Y. Liu, L. Cheng, and Y. X. Qu, Desalination 255, 78 (2010).
[3] L. Wadanambi, B. Dubey, and T. Townsend, J. Hazard. Mater. 157, 194 (2008).

[4] R. A. K. Rao, M. A. Khan, and F. Rehman, Adsorp. Sci. Technol. 29, 83 (2011). 
[5] A. S. Ozcan, O. Gok, and A. Ozcan, J. Hazard. Mater. 161, 499 (2009).

[6] A. H. Sulaymon, B. A. Abid, and J. A. Al-Najar, Chem. Eng. J. 155, 647 (2009).

[7] S. Chakravarty, A. Mohanty, T. N. Sudha, A. K. Upadhyay, J. Knoar, J. K. Sircar, A. Madhukar, and K. K. Gupta, J. Hazard. Mater. 173, 502 (2010).

[8] M. Franz, H. A. Arafat, and N. G. Pinto, Carbon 38, 1807 (2000).

[9] Z. Hu, M. P. Srinivasan, Microp. Masop. Mater. 43, 267 (2001).

[10] C. Brasquet, E. Subrenat, and P. L. Cloirec, Water Res. Technol. 35, 251 (1997).

[11] Q. Qian, M. Machida, and H. Tatsumoto, Bioresour. Technol. 98, 363 (2007).

[12] Y. Kikuchi, Q. Qian, M. Machida, and H. Tatsumoto, Carbon 44, 2681 (2006).

[13] J.-W. Shim, S.-J. Park, and S.-K. Ryu, Carbon 39, 1635
(2001).

[14] Z. Li, X. Chang, X. Zou, X. Zhu, R. Nie, Z. Hu, and R. Li, Analytica Chimica Acta 632, 272 (2009).

[15] T. Yamashita, Y. Ozawa, N. Nakajima, and T. Murata, Nippon Kagaku Kaishi 8, 1057 (1978).

[16] P. Patnukao, A. Kongsuwan, and P. Pavasant, J. Environ. Sci. 20, 1028 (2008).

[17] Y. S. Ho and G. Mckay, Process Biochem. 34, 451 (2003).

[18] X. L. Tan, Q. H. Fan, X. K. Wang, and B. Grambow, Environ. Sci. Technol. 43, 3115 (2009).

[19] X. L. Tan, X. K. Wang, M. Fang, and C. L. Chen, Colloid Surf. A 296, 109 (2007).

[20] I. Abe, K. Hayashi, and M. Kitagawa, J. Jpn. Oil Chem. Soc. 25, 145 (1976).

[21] S. Yamanaka, M. Machida, M. Aikawa, and H. Tatsumoto, J. Environ. Chem. 18, 219 (2008). 